\section{Wine and society}

\section{Maurizio Trevisan}

Health Sciences System, Nevada System of Higher Education, Las Vegas, NV, USA

Wine, its production and consumption, has accompanied western civilization for thousands of year. Since the early sign of its production in the Fertile crescent area, approximately 6000-8000 years ago, the culture of wine has spread out through the middle east, the Nile valley and the Mediterranean basin. Wine became part of the recorded history in ancient Egypt were it was used as part of religious ceremonies and by the Pharaos and the elite. Phoenicians through their extensive trading activities were, most likely, those responsible for the expansion of the wine culture to the rest of the Mediterranean basin and Greece and Rome in particular. Greek and Roman civilization played an important role in establishing an important role for wine in the daily life including the identification of potential medicinal properties; at the same time they were keenly aware of the potential disruptive effects of its excessive use and inebriation. The difference between the cultivated Ulyxes and the uncivilized Polyphemus was just in their different way of drinking wine. An indication of the relevance of wine in ancient Greek and Roman life is the fact that in both civilizations wine was tied to the specific religious myths of Dionysus and Bacchus. Romans played an important role in the development of methods for the production and storage of wine, its classification and for the development of wine production through Europe, including areas that are recognized today as the primary areas of wine production (i.e. France, Italy, Spain, etc). Religion played a critical role in preserving the production of wine methods and skills during the dark ages following the fall of the roman empire as monks continued to produce wine in their monasteries because of the important role of wine in the Christian faith. The chapter 40 of St Benedict's rules was dedicated to wine, monks should drink regularly in a moderate way (a quarter of liter daily). The relevance of the religious figures in the efforts to preserve wine culture can still be seen today through the names of specific well recognized brands of wines and specific ways of vinification.

The production of wine has influenced and been influenced by historical events. Examples of such strong ties with history include the almost near collapse of the French wine production as a result of the 100 years war, other historical events that have radically influenced the wine industry include the devastating effects of the phylloxera vastatrix infestation in 17th century Europe and the consequent rise of the wine industry in the United States of America, and its subsequent decline with the passing of the 18th Constitutional Amendment in 1917 and the following 15 years of Prohibition.

Throughout history, at least since ancient Greece, important figures (e.g. philosophers, artists, political and religious leaders etc.) have emphatically spoken about wine and either its qualities or its harms.

The volume of the wine market is such (in 2008 it was estimated at 283,898 hectoliters) that it has important economic implications for regions and countries in terms of production for both the local market and export (approximately 25\% of the wine consumed was purchased outside the country where the wine was produced). While few countries are responsible for a large portion of the wine produced in the world (Italy $21 \%$, France $20.4 \%$, Spain $11.7 \%$ ), in the past decades wine production has expanded substantially in many region of the world including countries that traditionally did not produce wine (i.e. China ).

The wine and grapes market has important financial implications as indicated by the impact of the wines and grapes industry on the USA national economy estimated at $\$ 162$ billions.

With such large world wide exposure it clearly important to evaluate and consider both the potential benefits and damages of wine consumption. Alcohol is considered among the top causes of injuries and premature death in developed countries with an estimated 76 million people world-wide affected by alcohol use
Correspondence: Maurizio Trevisan, MD MS Executive Vice Chancellor and CE0, Health Sciences System, Nevada System of Higher Education $5550 \mathrm{~W}$. Flamingo Road, Suite C-1 Las Vegas, NV 89103, USA

This work is licensed under a Creative Commons Attribution 3.0 License (by-nc 3.0).

(C) Copyright M. Trevisan, 2011

Licensee PAGEPress, Italy

Wine Studies 2011; 1:e1

doi:10.4081/ws.2011.e1

disorders, such as alcohol dependence and abuse. While there is no doubt that alcohol abuse, excess and binge drinking are have critical and significant impact on the life of millions (both directly and indirectly) there is still debate on the role of light and moderate drinking on the overall health of individuals and populations. Wine consumption, in moderation and when consumed with meals appears to have potential beneficial effects on a number of chronic conditions and overall health and is not associated with significant increase in risk of other conditions. It appears that these potential benefits may be linked both to the traditional way wine is consumed (during meals) and to specific components of wine (i.e. polyphenols). It should be pointed out that countries were wine represents the major source of alcohol use tend to have lower levels of heavy drinking, intoxication and binge drinking in both adults and teen agers.

It is clear that wine though its production and consumption has played and continues to play an important role in the life of our societies with a wide range impact on both individuals and populations. Its use and the societal attitude toward this very widely prevalent exposure is deeply rooted in our societal web and in a bidirectional way has shaped and continues to be shaped by our social and religious beliefs and norms. We hope that through our journal we will provide an opportunity and a forum to investigate and discuss the link between wine and the many aspects of our lives, from health to economics. 